\title{
And Now Post-Post-Acute Care Transitions
}

\author{
Stephen F. Jencks, M.D., M.P.H. ${ }^{7}$ and Joanne Lynn, M.D., M.A., M.S. ${ }^{2}$ \\ ${ }^{1}$ Independent Healthcare Safety Consultant, Baltimore, MD, USA; ${ }^{2}$ Center for Elder Care and Advanced Illness, Altarum Institute, Washington, DC, \\ USA.
}

J Gen Intern Med 31(12): 1410-1

DOI: $10.1007 / \mathrm{s} 11606-016-3770-7$

(C) Society of General Internal Medicine 2016

I $\mathrm{n}$ this issue of JGIM, Middleton and colleagues report ${ }^{1}$ that functional status impairments increase the risk of hospital readmission within 30 days of discharge from inpatient rehabilitation facilities (IRFs). The incremental risk is larger for some impairments than others and larger in patients with some conditions than others, but the first question to ask is why a busy general internist should pause to read the abstract unless she does discharge planning for IRFs.

In the last decade, health policy makers have developed an escalating awareness of the challenges and costs of care for patients who have been hospitalized and need help in a posthospital setting, and primary care physicians have little choice but to become wise in a field they could once almost ignore. A hailstorm of programs and their acronyms (BPCI, ${ }^{2}$ MIPS and $\mathrm{MACRA}^{3}, \mathrm{CPC}^{4}{ }^{4}$ ) make clear that the Medicare program will increasingly incentivize and coerce physicians into greater awareness of and responsibility for the total cost and effectiveness of their patients' care, including care components that have previously seemed outside the scope of medical care.

Just the title of this paper will stir unease in some practitioners who had not realized that attention to readmissions now extends to home health, skilled nursing facilities, and inpatient rehabilitation facilities. What will be the responsibilities of a general internist, particularly one practicing in a framework that might be called a "medical home?"

Some background may help: Over the past 50 years, Medicare has developed a set of benefits intended to reduce its hospital costs and perhaps improve patient outcomes by providing post-hospital services. Medicare pays four kinds of provider organizations for these benefits: 5,000 home health agencies, 15,000 skilled nursing facilities, 1,200 inpatient rehabilitation facilities, and 300 long-term care hospitals. ${ }^{5}$ These providers have developed from different starting points and are regulated and paid in different ways, and their performance has been measured in different ways. The 2014 Improving Medicare Post-Acute Care Act (IMPACT) was intended to bring the four types of provider organizations into a common performance measurement framework. A key concept motivating IMPACT was to see the different classes of

Published online June 16, 2016 organizations as sharing a common goal of improving function and to give the public comparison data among providers, provider types, ${ }^{6}$ and sequences of providers.

A patient who survives a hospitalization can either get better and mostly back to health, or not get better, which usually means getting worse. The former, cheerful perspective is consistent with the curative way of thinking and much Medicare policy. The latter, however, is consistent with the needs of many elderly or chronically ill persons who survive with gradually worsening health status. Some are just looking to slow the rate of decline, or to live as well as possible despite inevitable decline. Therefore, many hospital survivors are seeking the best way to live with their disabilities, losses, and limitations - including a way to live without crippling their families and loved ones.

The policy of focusing on improvement is in considerable tension with large stakeholder groups who have far more expansive visions of home health and skilled nursing, in which the aim is to provide home health services that allow patients to live well without institutionalization and to provide nursing home services that will come as close to desirable lifetime care as can be arranged. This is an ongoing tension within the human services community, and the majority of the federal legislative and executive branches appear determined not to let mission creep extend Medicare benefits to "non-medical" services. Thus, the requirement of IMPACT that providers report functional status will be two-edged. Functional status can be construed, as in the paper by Middleton and colleagues, to be an adjustment factor for risks of adverse outcomes. For example, IMPACT requires that Medicare-paid post-hospital providers report "Measures to reflect all-condition risk-adjusted potentially preventable hospital readmission rates." Having a common set of metrics allows the public and the policymakers to compare these providers in terms of their success in rehabilitating the patients who come to them, but it also serves as a strong claim as to what outcomes are to be taken to be important.

IMPACT may well foster programs that accelerate rehabilitation and reduce costs while accomplishing similar functional outcomes. But we cannot allow those gains to blind us to the needs of those for whom rehabilitation is not an option. Very different contexts have been created in the four settings of care. An important reason for rehabilitation centers like IRFs is to have "vigorous" "young" "salvageable" patients not have to share the dining room and sleeping quarters of aged persons who are living with serious and progressive disabilities and whose futures are much more limited. An important reason for 
long-term care hospitals is the way that ventilators and other machinery distort the civilized, residential tone of a nursing facility. Even if functional outcomes at 6 months are the same for many patterns of care, these social facts are important to the patients and families. Furthermore, a stay in a facility setting after hospitalization is not only meant to accelerate recovery from illness or injury, but also to allow the family caregivers to get organized and trained, or at least to have the burdens of caregiving reduced to what they can reasonably handle.

Middleton's team has reported a study that is of limited direct use to an office-based clinician, because it does not speak to how the clinician can intervene to make unplanned re-hospitalization rarer or less traumatic. At a different level, however, that clinician should realize that an increased focus on "post-post-acute readmissions" is arising and will require increased attention to patients recently discharged from posthospital facilities who will or should be showing up in the office. The $12 \%$ 30-day readmission rate from IRFs means that recently discharged patients will remain at significant risk. The basics that apply generally to post-hospital care apply here: have appointments available so that "post-post-acute" patients are seen in a timely fashion, know the relevant medications and ongoing therapy plans, pay attention to caregiver needs, and ensure adequate communication about the expected course and potential problems, which includes emergency contacts and contingency plans.

We may also need to reverse the lens through which the study results are viewed. It is not surprising, after all, that patients who are still not independent after intensive inpatient rehabilitation are also at higher risk for hospital readmission. The question, however, is whether the risk factor is the functional impairment or the underlying disease that causes the functional impairment. Middleton's team has not provided us an analysis of the reasons for readmission, but most patients who are rehospitalized after discharge from an IRF probably have had an underlying cause of disability that recurs or worsens, not just an increase in disability. This would be analogous to the finding that $70 \%$ of readmissions after surgery are for medical rather than surgical reasons. ${ }^{7}$

Post-hospital providers, like hospitals, are still on a steep learning curve in changing their practices to creatively support patients who will continue to live with serious chronic conditions. We should anticipate that community practitioners who see themselves as the patient's primary source of care will need to nurture their referral and transfer networks.

Corresponding Author: Stephen F. Jencks, M.D., M.P.H.; Independent Healthcare Safety Consultant, 8 Midvale Rd, Baltimore, MD 21210, USA (e-mail: steve.jencks@comcast.net).

\section{REFERENCES}

1. Middleton A, Graham JE, Lin Y-L, Goodwin JS, Bettger JP, Deutsch A, Ottenbacher KJ. Motor and cognitive functional status are associated with 30-day unplanned rehospitalization following post-acute care in Medicare fee-for-service beneficiaries. J Gen Intern Med. 10.1007/s11606-0163704-4.

2. Centers for Medicare \& Medicaid Services. Bundled Payments for Care Improvement (BPCI) Initiative. Available at https://innovation.cms.gov/ initiatives/bundled-payments. Accessed May 24, 2016.

3. Centers for Medicare \& Medicaid Services. MACRA-MIPS and APMs. Available at https://www.cms.gov/Medicare/Quality-Initiatives-Patient-Assessment-Instruments/Value-Based-Programs/MACRA-MIPS-and-APMs / MACRA-MIPS-and-APMs.html. Accessed May 24, 2016.

4. Centers for Medicare \& Medicaid Services. Comprehensive Primary Care Plus. Available at https://innovation.cms.gov/initiatives/comprehensiveprimary-care-plus/. Accessed May 24, 2016.

5. MedPAC. March 2016 Report to the Congress: Medicare Payment Policy. MedPAC: Washington DC; 2016. Available at http://www.medpac.gov/documents-/reports. Accessed May 24, 2016.

6. Post-Acute Care Payment Reform Demonstration: Final Report. Gage B; Morley M, Smith L. et al. Available at https://www.cms.gov/ResearchStatistics-Data-and-Systems/Statistics-Trends-and-Reports/Reports/Research-Reports-Items/PAC_Payment_Reform_Demo_Final.html. Accessed May 24, 2016.

7. Jencks SF, Williams MV, Coleman EA. Rehospitalizations among Patients in the Medicare Fee-for-Service Program. N Engl J Med. 2009;360: 1418-28 